\title{
Ba stable isotopes and their relationship with salinity in the East China Sea
}

KEIJI HORIKAWA ${ }^{1 *}$, YUKI TEZUKA $^{2}$, TAKASHI $^{4}$
MIYAZAKI $^{3}$, SHIGEYUKI WAKAKI $^{4}$

${ }^{1}$ Graduate School of Science and Engineering for Research, University of Toyama, Gofuku 3190, Toyama 930-8555, Japan (*correspondence: horikawa@sci.u-toyama.ac.jp)

${ }^{2}$ Graduate School of Science and Engineering for Education, University of Toyama, Gofuku 3190, Toyama 930-8555, Japan

${ }^{3}$ Department of Solid Earth Geochemistry, Japan Agency for Marine-Earth Science and Technology 2-15 Natsushimacho, Yokosuka, Kanagawa 237-0061, Japan

${ }^{4}$ Kochi Institute for Core Sample Research, Japan Agency for Marine-Earth Science and Technology, Nankoku, Japan

Riverine input is the dominant source of barium to marginal seas. If there is a single riverine input to a marginal sea, $[\mathrm{Ba}]$ tends to negatively correlate with salinity in the surface water. Therefore, $\mathrm{Ba} / \mathrm{Ca}$ ratio in planktonic foraminifer is often used as a salinity proxy [1]. Although it is expected that $\mathrm{Ba}$ isotopes also have a potential for a paleosalinity proxy, there is little data regarding $\mathrm{Ba}$ isotope-salinity relationships in marginal seas.

In this study, we measured $\mathrm{Ba}$ isotopic compositions $\left(\delta^{138 / 134} \mathrm{Ba}\right.$, relative to NIST3104a) of surface seawaters in the East China Sea, Kuroshio region, and the Japan Sea. These seawater samples were obtained in summer seasons during multiple research cruises from 2013 to 2019 . The $\delta^{138 / 134} \mathrm{Ba}$ showed the highest value of $\sim 0.73 \%$ in the Kuroshio region ( $S=\sim 34.7$ ), and the lowest value of $\sim 0.27 \%$ in the inner shelf of the ECS $(S=\sim 31)$. Our $\delta^{138 / 134} \mathrm{Ba}$ data in the ECS were significantly lower than the previously reported $\mathrm{Ba}$ isotopic compositions in the ECS [2], but consistent with other North Pacific seawater data [3]. Although our data only cover the range of salinity from 30 to 34.7 in the ECS, the $\delta^{138 / 134} \mathrm{Ba}$ and salinity can be explained by the binary mixing with endmembers of Kuroshio and Changjiang River waters. Further, the surface water samples in the Japan Sea also plotted on this binary mixing line, suggesting that Changjiang River water accounts for $\sim 5 \%$ to the Japan Sea. If [Ba] and its isotope supplied from the Changiiang River were not temporally fluctuated, our binary mixing line can be used to estimate paleo-salinity from $\delta^{138 / 134} \mathrm{Ba}$ of planktonic foraminifer, bivalves, and corals.

[1] Weldeab et al., 2007, Science, 316, 1303-1307. [2] Cao et al., 2016, EPSL, 434, 1-9. [3] Hsieh, Y.-T., and G. M. Henderson, 2017, EPSL, 473, 269-278. 